Est Ag 37 (2002) 523-548

\title{
Alonso de Orozco
}

\section{Asceta y místico del siglo de Oro Español}

\section{Primera parte: Rasgos de una vida ejemplar}

En otro lugar ha quedado escrito lo siguiente: "Fray Alonso de Orozco, el hombre culto, sabio y bondadoso, el asceta más que místico, el reformador eminente, el hombre contemplativo y predicador de la palabra cálida y viva, con obras testimoniales y elocuentes; el hombre cercano al pueblo llano y, también, consejero de la Carte Real -la de Carlos V y Felipe II-, el escritor y el limosnero, el teólogo y el pastor, el fundador y el religioso observante, el hijo fiel y obediente de la Virgen - "Alonso, escribe", oyó de sus labios-, el amigo de los pobres y marginados, figura de talla universal en el campo de las letras y de las ciencias religiosas, defensor de la lengua castellana...; el hombre del bien hablar, del bien decir y del bien hacer"..., es'nuestro personaje 1 .

Efectivamente, el reconocido mérito de nuestro ilustre agustino en las letras hispanas, de modo especial, en la teología ascética y mística, de las que fue verdadero pionero en nuestro siglo de Oro; su ardiente pasión apostólica, que le lleva a proyectarse en el cultivo de la vida religiosa, en la predicación de la Palabra a la gente sencilla y en la entrega caritativa con los pobres y más necesitados; su presencia ejemplar en la Corte, donde era querido y venerado de todos -pequeños y grandes- por igual; querido y venerado, también, en la villa de Madrid; su abundante producción literaria, filosófica, teológica, ascética y mística para todos los estados de la vida, nos le avalan y declaran abiertamente como "preclara gloria en la virtud y en la palabra, gran figura del siglo XVI español", y como "una persona de una vida iluminada por la ciencia, y de una fe enriquecida por la vida", según se ha podido decir recientemente de él.

El siglo de Oro español ofrece una cartelera espléndida de hombres ilustres: literatos, artistas y santos. Precisamente, cuando en el mar se abren cami-

1. Moreno, Mariano, Figura y obra de Alonso de Orozco, O. S. A. Actas de las Jornadas del IV Centenario de su muerte. Editadas por Rafael Lazcano Edt. "Revista Agustiniana" (Madrid 1992), p. 12 
nos hacia las Américas, comienza a escribirse una de las páginas misioneras más brillantes de todos los tiempos.

Pues bien, en este marco histórico -acaso único en la España de los Reyes Católicos y de sus herederos Carlos V y Felipe II-, debemos situar a Fray Alonso de Orozco, fraile agustino, nacido en Oropesa de Toledo el día 17 de octubre del año jubilar 1500 .

El propio Orozco dirá en su libro las Confesiones: "Mi nacimiento fue en Oropesa, reinando la muy católica reina doña Isabel, de gloriosa memoria" 2.

Sobre el particular,no hace mucho tiempo he recibido un breve artículo, firmado por Modesto González Velasco, en el que se pregunta: 'En qué año nació el Beato Alonso de Orozco'. Con lo que pone en duda la fecha señalada arriba.

Después de leer dicho artículo, uno también puede preguntarse: ¿hasta qué punto cabe esta duda, cuando todos los biógrafos que conocemos de nuestro santo -el día 19, de mayo fue solemnemente canonizado por el papa Juan Pablo II- señalan la fecha indicada, desde. Fray Hernando de Rojas, su confesor y confidente, el cual dice a la letra: "nació nuestro padre fray Alonso de Orozco (en) jueves, diecisiete de octubre, año de 1500, víspera de San Lucas ${ }^{3}$, hasta el P. Tomás Cámara, sin duda el mejor biógrafo de todos los tiempos de nuestro agustino, el cual escribe: " Era jueves, diecisiete de octubre del año del jubileo mil y quinientos, puesto el sol y entre dos luces" 4.

Igualmente, el P. Juan Márquez, que dice: "Nació a diecisiete de octubre del año 1500, a la hora de las Ave Marías" 5. Y el benemérito historiador P. Tomás de Herrera, que escribe textualmente: "Nació el Vble. P. Fr. Alonso de Orozco en la villa de Oropesa; del Obispado de Avila, a diecisiete de octubre del año $1500^{6}$.

Otro tanto leemos en el P. Gregorio de Santiago Vela -dejando otros biógrafos menores-, que dice: "Nació el 17 de octubre de 1500 en Oropesa, de la provincia de Toledo" 7 .

2. Orozco, Alonso de, Confesiones. Edt. "Amigos del País", (Manila 1882), p. 1.

3. ROJAS, Hernando de, Información Sumarial, 2-2, p. 721.

4. CÁmARA, Tomás, Vida y Escritos del Beato Alonso de Orozco. Imp. y Lib. de la Viuda de Cuesta e hijos (Valladolid 1882), p. 9.

5. Marquez, Juan, Vida del Vble. P. Fr. Alonso de Orozco. Imp. Juan Sánchez (Madrid 1648), p. 7.

6. Herrera, Tomás de, Historia del Convento de San Agustín de Salamanca. Imp. Gregorio Rodríguez (Madrid 1652), p. 39.

7. VELA, Gregorio de Santiago, Ensayo de una Biblioteca Ibero-Americana de la Orden de San Agustín. Imp. El Escorial, vol. VI, p. 96. 
Modesto González divaga sobre la cronología de A. Capelli ${ }^{8}$, para terminar preguntándose de dónde sacó Hernando de Rojas la fecha del 17 de octubre de 1500 . Y confiesa genuinamente que no lo sabe.

Alonso de Orozco era hijo de Hernando de Orozco, perteneciente a una familia noble, el cual fue gobernador del Castillo y Alcaide de Torico. Su madre se llamaba María de Mena, "hidalga doncella". y toledana de nacimiento; esposa fiel y madre ejemplar de una familia numerosa, de unos hijos que ofreció, en un alarde de generosidad y de devoción, a Nuestra Señora.

En la vida del santo de Oropesa, tenemos un testimonio tan hermoso como elocuente. Pertenece a don Francisco de Quevedo y Villegas, el cual conoció, siendo niño todavía, al "santo de San Felipe", pues le visitaba en su celda, a la que le mandaban sus padres, "para que se hiciese con su ejemplo mạ́s bueno".

Esta gran figura de las letras españolas declaró en la Sumaria que "el P. Orozco era de casa solariega e infanzona, donde ha habido muy señalados e ilustres caballeros, como se le lee en la Crónica del rey don Alfonso el Onceno, y del rey don Pedro el Cruel, su hijo, especialmente el esforzado caballero Iñigo López de Orozco y su hermano; el cual dicho Iñigo López de Orozco fue caballero de Banda, que en aquel tiempo se tenía por la primera prerrogativa de nobleza en Castilla 9.

El P. Tomás Cámara, abundando en este mismo tema, dice que la familia de los "Orozco" descendía del señorío de Vizcaya, y que su antiguo solar se hallaba enclavado en el ameno valle del mismo nombre, ocupando el corto término de unos veinte kilómetros de largo por once de ancho. Estaba rodeado de altos montes, poblados de hayas, encinas, alisos y robles. De sus escarpadas cumbres -el Altube y la peña de Gorbea-, descendían en estrecha torrentera el río Arnauri y el Altube, los cuales, unidos entre sí, cuando lleguen al valle, y favorecidos por pequeños arroyos, formarían el rio Orozco, ya de más caudal y afluente del Nervión" 10.

Creo que en un ensayo como éste, lo que menos importan son el recuento de fechas -que bien pueden estar equivocadas-, lugares y actividades del que, con el tiempo, fuera llamado "el santo de San Felipe", ya que todo ello

8. Capelli, A., Cronología, Cronografia e Calendario Perpetuo del principio dell' Era cristiana ai nostri giorni. Editrice Ulrico Hoepli, (Milano 1988).

9. Por lo que se refiere a los datos que aporta don Francisco de Quevedo y Villegas, en el Informe Sumarial, fol. 463, sabemos que el eximio poeta conceptista español nació en Madrid el año 1580; por lo que no pudo ya conocer a los padres de san Alonso de Orozco, y a éste solamente hasta los once años, que son los que contaba cuando nuestro Venerable murió en el colegio de doña María de Aragón, el día 19 de septiembre de 1591.

10. Cámara, T. o. c., libro I, c. $1^{\circ}$, p. 2 y 3. 
no es suficiente para conocer y entender la vida de un hombre; en este caso, de Fray Alonso de Orozco.

$\mathrm{Si}$, como dejó escrito el gran historiador Arnold Toynbee, "el hombre es un ser que acontece, y a este acontecer llamamos historia", es claro que a nuestro personaje hay que saber situarlo en 'el marco histórico en que nació y se desarrolló su existencia, que fue, prácticamente, todo el siglo XVI.

Decir, sí, que Alonso de Orozco vivió enraizado en el mundo histórico y espiritual de su tiempo. Su vida cubre, prácticamente, todo el siglo XVI, el siglo de las grandes empresas espirituales y temporales de España.

España estaba gobernada por los Reyes Católicos, doña Isabel y don Fernando: Dos soberanos a los que ayudó la naturaleza "con un número increíble de vasallos insignes en letras y armas", y que supieron dar "a las obras del espíritu más amplia intervención en la vida y una restauración de las fuerzas materiales dél país, empobrecido por las guerras".

Los años de la infancia de Orozco los pasó en Oropesa, Talavera de la Reina y Toledo, siguiendo los distintos destinos de sus padres por tierras manchegas.

Hasta que un día, ya muchacho, sus padres le enviaron a Salamanca, a estudiar, en compañía de su hermano Francisco, mayor que él, quien le había precedido en la Sorbona de España.

Fray Hernando de Rojas declara que Orozco se vino de Toledo con su hermano mayor a Salamanca para estudiar; añadiendo que, estando allí estudiando Derecho, su hermano trató de ser fraile de san Agustín ${ }^{11}$.

Alonso, que sin duda venía maquinando en su mente la misma idea "le rogó por muchas veces -añade el confesor de nuestro santo-, que negociase la frailía (sic) para entrambos.

Salamanca y su Universidad ascendían entonces presurosas, a impulsos de su ingenio, a la más alta cumbre de la sabiduría. La Universidad salmantina se había convertido, a comienzos del siglo XVI, justamente cuando nace Alonso de Orozco, en un emporio cultural y en oráculo de Europa entera.

Dos hermanos de la familia Orozco frecuentaron sus aulas, donde cursaba estudios una juventud movida, antojadiza y bullanguera. Salamanca, "Roma la chica", era lugar de encuentro para la nobleza de Castilla, mientras que Alcalá era más popular y más atenta a la corriente renacentista.

"Francisco era el de más años. La barba que le cubría su rostro prestaba a su fisonomía cierto aspecto de gravedad. Alonso, a quien apuntaba el primer bozo de la juventud, parecía más alegre, más simpático. Un tinte de vir-

11. RojAs, Hernando de, Relación de la vida de Fray Alonso de Orozco. Texto, en Información Sumarial del proceso de beatificación, p. 8 . 
ginal pudor bañaba sus frescas mejillas y en sus rasgados ojos se pintaba un sentimiento de dulzura inexplicable".

Hasta que un buen día se presentó en la ciudad del Tormes un famoso profesor de Alcalá, por nombre Tomás García Martínez; pero no para tomar posesión de una cátedra, sino para entrar como novicio en el renombrado convento de San Agustín, del que será muy pronto -a los dos años de ser ordenado de sacerdote-, prior, pero ya con el nombre de Fray Tomás de Villanueva.

Corría el año 1521. Probablemente, Francisco y Alonso oirían la palabra sabia, ardiente, ungida y devota del futuro arzobispo de Valencia. El hecho es que un 8 de junio de 1522 -víspera de la festividad de Pentecostés- ambos hermanos tomaron el hábito.

Según cuenta el propio Orozco, durante el noviciado, sufrió toda clạse de turbulencias espirituales. Le martillearon dudas, escrúpulos y la tentación de abandonar el claustro. Al final del combate, dará gracias a Dios, profesando en manos de santo Tomás de Villanueva que ejercía por segunda vez el cargo de prior, el día 9 de junio del año 1523.

De Fray Alonso de Orozco, solamente podemos decir que fue un religioso ejemplar. Ordenado de sacerdote, el 1527, como su maestro de novicios, Fray Luis de Montoya, y su superior, Fray Tomás de Villanueva, se convierte en predicador de la Palabra de Dios. "También de vuestra mano -escribirála obediencia me puso en el oficio de predicador, del cual Vos, Señor, os preciasteis, alumbrando las ánimas para que gozasen de Vos en el cielo".

La obediencia religiosa le llevó a recorrer varios conventos y a ocupar cargos importantes en los mismos. Prior de Soria, lo será más tarde en Medina del Campo, donde le vemos por el año 1540, para pasar luego al monasterio de Sevilla. Otro cargo que desempeñó dentro de la Orden fue el de Definidor o Consejero del prior Provincial.

En el sabroso comentario que hizo a la Regla de San Agustín, dice que "tres cosas hacen a los siervos de Dios encargarse de las prelacías. La primera es cuando entienden que Dios los llama para aquel oficio; y sin ellos entender en ello, ni aun quererlo, son elegidos para tales oficios: como nuestro Padre y san Ambrosio, y todos los santos lo fueron. Lo segundo, por un gran celo de caridad, cuando hay necesidad. Y esto es más perfecto que lo primero. Lo último por lo que los varones de Dios reciben las prelacías, es por la obediencia que se lo manda: Y este es el motivo más alto de todos" 12.

12. Orozco, A. de, Regla de N. P. S. Agustín y su Exposición en castellano. (Madrid 1781), c. VII, p. 81. 
Fray Alonso de Orozco, alma apostólica y misionera, deseó acompañar a sus connovicios Agustín de Coruña y Alonso de Borja, misioneros en Nueva España desde el año 1533; pero una enfermedad -que le hará sufrir mucho durante toda su vida-, se lo impidió cuando ya estaba en alta mar a la altura de las islas Canarias, rumbo a la gran aventura evangelizadora del Nuevo Mundo.

Deseaba pasar a México, "para en algo ayudar a mi Orden -declara humildemente-, que allá con tanto fruto predicaba a los indios vuestra sante fe" 13 .

Deseaba, igualmente, "morir mártir, privilegio tan alto, que no se alcanza sin la gracia de Dios" 14.

Dios le tenía destinado para ejercer otra clase de apostolado: el de predicar a los pobres y sencillos, a las religiosas de clausura, a los presos, a los fieles que acudían a escucharle en las distintas iglesias donde exponía la Palabra.

Hombre humilde y austero, valedor de huérfanos y magnánimo con los pobres y marginados, su fama se extendió por toda la Corte. Por lo que todo el mundo le conocía por el sobrenombre ya reseñado de "el santo de San Felipe", debido a que su residencia habitual en Madrid fue el célebre covento de este nombre ${ }^{15}$.

Capellán de Carlos V y de Felipe II, residiendo en Valladolid, corte española en 1554, sería también el confesor y consejero de doña Juana, hermana de Felipe II, infanta de España y princesa de Portugal, la cual ejercía el cargo de Gobernadora, en calidad de Regente de España, y en ausencia de su padre, el emperador Carlos V.

En Valladolid residía Fray Alonso de Orozco, cuando le llegó el nombramiento de predicador real del César y capellán, más tarde, de su heredero Felipe II, al que no le quedó más remedio que seguirlo a Madrid, cuando el monarca decidió trasladar la corte a esta capital.

Ya en la villa del Oso y el Madroño, se convertirá, no sólo en el capellán del rey, sino que, desde su obediencia y pobreza, será el amigo y confidente de palacio. Lo cual no obstaba para vivir en su convento, ausente por completo de la comidilla que se traían los palaciegos. De tal modo, que su vida será la de un fraile humilde y penitente, que ocupará la celda más pobre del conven-

13. Orozco, A. de, Libro de las Confesiones. Ed. Amigos del País, (Manila 1882), p. 1.

14. Ibid., l. c., p. 66.

15. El convento de San Felipe el Real, de los Agustinos de Madrid, ubicado exactamente detrás de la Puerta del Sol, en Pontejos, era muy celebrado, pues en su escalinata tenía lugar el "Mentidero de Madrid", donde acudían los más destacados literatos de la época, como Góngora, Quevedo, Lope de Vega, Juan de Alarcón, y donde se dedicaban sus ditirambos y sus "pullas", junto con otras "lindezas". 
to, tratando de ser viva imagen del Evangelio, imitando a Cristo en todas las virtudes, especialmente en la penitencia, en medio de sus continuos sufrimientos y enfermedades, en la humildad y en la misericordia y caridad con los pobres y necesitados.

Alonso de Orozco no dejaba de acudir a palacio. Pero, hombre contemplativo y amante de la soledad, ansiaba dejarlo, pues la parecía -como él mismo dice-, "una cárcel del vivir entre el ruido y los cumplimientos de la corte que es apenas tolerable". Mas el rey don Felipe no permitió nunca que abandonara la corte -como era deseo del siervo de Dios-, pues decía: "No quiero se ausenten de ella los santos".

Mucho le honraba el rey, con toda su familia. Pero no menos honras recibía de los nobles cercanos a palacio ${ }^{16}$. Sin embargo, el siervo de Dios encontraba mayor gozo con los pobres, de los que se compadecía hasta derramar lágrimas.

Era tanta la caridad que tenía con ellos -declara doña María de la Columna-, que hasta se proveía de carbón, en el invierno, y lo encendía cada mañana en la portería del convento, donde los pobres le estaban aguardando para calentarse 17 .

Una de las damas de la reina, doña Juana de Mendoza, madre de doña Catalina de la Cerda, declara que era tan abundantísima su caridad, "que andaban tras él tantos pobres, que parecían un escuadrón. '¡Ved, ahí viene el santo Orozco, el santo de San Felioe!', exclamaba la gente al verlo pasar camino de palacio, de la iglesia de la Magdalena, del hospital, o de la cárcel, donde acudía para socorrer y libertar, si estaba en su mano, a algún preso. Todos se hincaban de rodillas para besarle las manos y el hábito, llamándole santo" 18 .

Con los enfermos, extremaba su caridad, visitando los hospitales, donde, llegado a la cama del paciente, le leía los evangelios, le imponía luego las manos $\mathrm{y}$, finalmente, le repartía bizcochos y otros regalos que llevaba siempre el compañero agustino, que es quien informará después de todo ello 19.

Es más, don Francisco López Salcedo, platero del rey, gran amigo del P. Orozco, declara que, en los treinta años que le conoció, le daba con frecuencia dineros, "para que fuese a la cárcel de esta villa (Madrid), y sacase los presos que estuviesen detenidos por las costas".

16. LóPEZ, Francisco, Informe Sumarial de Madrid, fol. 104.

17. Declaración de doña María de la Columna. Informe Sumarial de Madrid, fol. 345

18. Esta declaración la hace el P. Diego Gutiérrez, agustino, compañero de nuestro santo, confesor que fue también del convento de San Agustín de la villa madrileña de Chinchón.

19. Ibid., Informe Sumarial de Madrid, fol. 104. 
Por lo que bien podemos afirmar que dos amores básicos ardían en su corazón: el amor a Dios y el amor al prójimo; de modo especial, a los más humildes y a los pobres.

A éstos es a los que con más cariño predicaba la Palabra; pues, como solía decir, cuando acudía a predicar a las monjas de clausura: "los reyes tienen predicadores, porque pueden pagarlos; pues estas pobres monjas, que no pueden, que les tengan también".

Fundador y reformador de conventos, devoto de la santísima. Virgen Máría, la cual, residiendo nuestro santo en Sevilla, le mandó que escribiese - "Alonso, escribe", le dijo-; cargado de días y de méritos, el día 9 de agosto de 1591 cayó enfermo de gravedad, y el 19 de septiembre voló su alma al cielo.

La muerte del P. Alonso de Orozco fue cual había sido su vida. Como apuntan los biógrafos, "pues si nació en jueves, murió también en jueves, que era muy devoto de ellos por su amor al Santísimo Sacramento. Murió a los 91 años de edad, Quedó después de muerto más blanco que un cristal" 20.

En realidad, el P. Orozco se fue muriendo a lo largo de su vida en cada enfermo que visitó, en cada pobre que socorrió, en cada preso que liberó de la cárcel y en cada moribundo que ayudó a bien morir. Pero tenía que irse algún día para descansar de sus muchas fatigas y trabajos, de su intensa vida de apóstol de los sencillos. Como él mismo dejara escrito, debía partir "de este destierro, que es la vida mortal del hombre sobre la tierra".

Sus restos mortales fueron depositados en el Colegio de la Encarnación -hoy "Sede del Senado español"-. Actualmente, después de varios recorridos y de posar durante muchos años en el colegio de Valladolid, descansan en el convento de Agustinas de Madrid (Granja,9).

Declarado Venerable por el papa Clemente XII el 5 de agosto de 1732; beatificado por León XIII el 15 de enero de 1882, fue canonizado por el papa Juan Pablo II el 19 de mayo de 2002.

\section{Segunda parte: Alonso de Orozco, asceta y místico}

\section{a. Alonso de Orozco, asceta, "columna alentada de todas las virtudes".}

El ilustre purpurado español, Benito Sanz y Forés, en el Discurso inaugural de la Velada Literaria, que, con motivo de la beatificación del venerable Alonso de Orozco, se celebró en el Colegio de Agustinos de Valladolid el día

20. ROJAS, Hernando de, Relación..., 1. c., c. 91. 
17 de noviembre de 1882, dijo que es posible no se vea en los escritos de nuestro agustino la pompa y artificio de Fray Luis de Granada, el número y compás del maestro Fray Luis de León, la traza y punto de Fray Cristóbal de Fonseca, todos ellos contemporáneos del asceta y místico agustino; pero se aspirará, sin duda, "deleitoso aroma de suavidad e inestimable ternura de afectos que saben a gloria".

Por lo que, conociendo su vida y sus obras, Fray Gregorio Petrocchini, General de la Orden, encontrándose en Toledo el día de la Epifanía de 1589, oyendo predicar al siervo de Dios, dijo de él lo siguiente: "Un varón santo y hombre de doctrina insigne".

Nada de extraño tiene, pues, que, al tiempo de presentar los escritos de Orozco, los postuladores de la causa de su beatificación, para defensa de los mismos, se atrevieran a pedir al Sumo Pontífice que lo admitiera entre el número de los Doctores de la Iglesia.

No le cupo ese honor. Como tampoco le cupo a su maestro y superior, Fray Tomás de Villanueva; pero nadie dudará hoy de que uno y otro se lo tenían bien ganado.

Por otra parte, como escribe el P. Cámara, la bondad de su carácter, hermosamente realzada por la pureza de costumbres, unidas a la ciencia que recientemente acababa de adquirir, le llamaba a estar presente en los púlpitos, más que en la cátedra de la Universidad, que estaba reservada para su contemporáneo y hermano de hábito, el Mtro. Fray Luis de León.

En este aspecto, sus biógrafos nos dicen a coro que sus sermones eran "panales de dulzura, de suavidad y de amor". Y es una maravilla leer lo que sigue: "¡Oh, plegue a Jesucristo que, en todos los años que predicáremos, presentemos siquiera una alma ante los ojos de Dios, adquirida con nuestros trabajos" 21.

Pero si le negaron el honroso título de Doctor de la Iglesia, "le cupo la honra de haber sido el primer apologista de la lengua española, antes de que lo hicieran de modo tan contundente y brillante el Mtro. Fray Luis de León, Malón de Chaide y Fray Cristóbal de Fonseca" 22.

En su libro Tratado de las Siete Palabras que María Santísima habló, saliendo al paso de cuantos pudieran rasgarse las vestiduras por escribirlo en castellano y no en latín, como era de rigor, declara paladinamente: "No os dé pesadumbre, sabio lector, ir por vía de sermones este libro; pues no os la da

21. Orozco, A. de, Memorial de amor santo, t.II. c. XIV, (Edt. Calatrava, (Salamanca, 1896), p. 234.

22. SANZ y FORES, Benito, Discurso Inaugural en la Velada Literaria... (Valladolid 1880), p. 13. 
oir cada día predicar. Sabed que san Crisóstomo, san Atanasio, san Basilio y otros doctores griegos de gran erudición y autoridad, en su idioma vulgar escribieron sus sermones y homilías, y después fueron traducidos al latín. Muchos predicadores italianos escribieron sermonarios en su lengua toscana. Cada nación usó mucho escribir su propia lengua: solamente los españoles, amigos de trajes peregrinos y costumbres extranjeras, tenemos en poco lo que se escribiese en nuestra lengua, siendo la que más estimada debe ser en elegancia y perfección, después de la latina. De mí digo que alabo al Señor, cuando leo libros en romance de buena y provechosa doctrina. Mayormente, que mi fin no es hablar en este libro con predicadores y personas sabias, de quien yo tengo de oir y aprender: a los pequeños deseo consolar y aprovechar, aunque bien me acuerdo que leyendo Virgilio al poeta Ennio, de más bajo estilo entre los poetas, dijo a un amigo suyo: ando buscando oro en este polvo. No hay libro tan sin provecho que no sea de grande utilidad al que es sabio, si quisiera leerle atentamente" 23 .

Antonio de Mier, en su conferencia, presentada en las Jornadas del IV Centenario de la muerte de Orozco, titulada Alonso de Orozco en el marco histórico general de su época, dice que no a todo el mundo le parecía que la lengua romance castellana era lo suficientemente digna como para arropar elevadas exposiciones de carácter religioso como: los tratados ascéticos, las balbucientes aproximaciones místicas, y los comentarios teológicos a los Libros Sagrados. Para eso ya estaba el latín, la lengua consagrada por la sabiduría clásica y por la Iglesia.

Orozco supera ese remilgo y compone preferentemente en castellano, aunque también nos haya dejado hermosos tratados escritos en latín. Desea escribir en la misma lengua en la que corrientemente se habla en la calle, en el confesonario, en el locutorio y en la Corte ${ }^{24}$.

La extensa obra de Orozco nació al calor de un alma abrasada en el amor divino, llevada del sentimiento y de la inspiración. Sus libros son "como flores espontáneas, donde apenas se echa de ver la mano del hombre".

Por eso, no habiéndose hecho violencia su autor, salió toda la obra como un vivo retrato de su carácter llano, modesto y apacible.

Es verdad que no ha tenido suerte nuestro clásico autor y apologista de la lengua castellana entre los críticos y entendidos de la literatura española,

23. Orozco, A. de, Tratado de las Siete Palabras que María Santísima habló. Edición Laureano Herrán, (Rialp, S. A., Madrid 1966). Prólogo, p. 54-55.

24. Mier, Antonio de, Figura y obra de Alonso de Orozco, O.S.A. (1500-1591). Actas de las Jornadas del IV Centenario de su muerte. (Edt. Revista Agustiniana, Madrid 1992), p. 37 . 
tal vez, por no tener noticia exacta de las muchas obras que escribió en este idioma. Pero no hay duda de que estuvo muy acertado uno de sus biógrafos al afirmar que el estilo de Fray Alonso de Orozco es castizo, terso y elocuente. "En sus obras castellanas, no envidiarás afectadas limas con la más singular naturalidad. En las latinas, no echarás de menos la facundia de Tulio y la solidez de Plutarco. No se habla hoy el latín que escribe Orozco".

Por su parte, Juan Márquez señala que Fray Alonso de Orozco era "agudo en las sentencias, propio en las palabras, suave en el estilo, casto en las frases, no forzado en las metáforas y en nada inferior a los que con mayor primor escriben en una y otra lengua. Habla con una sencillez cristiana, tan sin artificio, que parece milagro no faltar a la elegancia, dando tanto a la llaneza" 25 .

Entre los extraños a la Orden, vale la pena citar a Fray Hipólito Marracio, el cual escribe lo siguiente: "Alonso de Orozco, del Orden de los Ermitaños de San Agustín, español de nación, celoso predicador de Carlos V y Felipe II, clarísimo en la elocuencia y conocimiento de varias ciencias, columna alentada de todas las virtudes, especialmente de la humildad, penitencia, oración, mansedumbre y misericordia, entre otros partos de su entendimiento, con lo que ilustró no sólo a la familia agustiniana, sino al cristiano nombre, y dio a la Biblioteca Mariana la exposición de los cánticos" 26.

En el siglo XVI llamaban "hombres de letras" a los grandes teólogos y entendidos en las sagradas Escrituras. En este sentido, hay que afirmar que Fray Alonso de Orozco era un gran teólogo, como lo aseguran sus biógrafos más antiguos, el citado Juan Márquez y Basilio Ponce de León ${ }^{27}$.

De hecho y en confirmación de esta tesis, nuestro escritor asceta y místico, conocía a la perfección las lenguas bíblicas: hebreo, caldeo (actualmente arameo) y griego: Escribía la lengua de Cicerón con una gran soltura, y hasta se puede decir con elegancia, como lo acreditan algunas de sus obras que escribió en este idioma.

Todo esto es tan verdad, que, con seguridad, no hay autor clásico que cite tantas veces la Biblia, como la cita nuestro asceta y místico agustino.

Pero hay más. Orozco fue un hombre que poseía una gran cultura. Como lo demuestra, asimismo, en sus escritos. Tengamos en cuenta que ingresó en la Orden cumplidos los veintidós años, después de haber estudiado en la Universidad de Salamanca seis o siete años Derecho, adquiriendo, de este

25. Márquez, Juan, Vida del Vble. P. Fr. Alonso de Orozco. (Imp. Juan Sánchez, Madrid 1648).

26. Fray Hipólito Marraccio se está refiriendo en concreto al libro de Orozco Tratado de las Siete Palabras que María Santísima habló.

27. PONCE DE LEóN, Basilio, Anotaciones a las Confesiones, de este gran pecador Fray Alonso de Orozco (Madrid 1591), p. 173-75. 
modo, una cultura básica civil, que más tarde ampliará con las lecturas de obras de autores paganos.

Posiblemente, uno de los que mejor y en mayor profundidad han estudiado el pensamiento espiritual de Alonso de Orozco sea Gonzalo Tejerina, en la Introducción a los Obras Completas, que han comenzado a publicarse en la Biblioteca de Autores Cristianos (BAC) ${ }^{28}$. Tejerina comienza su estudio diciendo que Alonso de Orozco alcanzó su labor de escritor a una edad relativamente tardía, cuando contaba ya cuarenta y dos años, diecinueve de vida religiosa, quince de sacerdocio y otros tantos como reputado predicador de oficio.

Más adelante, señala que su obra se presenta a todas luces como la de un escritor espiritual, una obra que con una rica fundamentación bíblica y una infraestructura teológica notable, desarrolla la pretensión decisiva de edificar espiritual y moralmente. "En su pensamiento, el primado pertenece sin duda a lo teológico espiritual, sea de dirección ascética o de dirección mística, queriendo llevar a una experiencia cristiana depurada con las correspondientes derivaciones morales".

Después; va señalando en distintos bloques o apartados las obras de Orozco: históricas, de carácter catequético y homilético, de carácter teológicoespiritual, de carácter moral y de carácter jurídico.

Posteriormente, nos ofrece el "pensamiento del beato y referencias doctrinales". En este aspecto, declara que en el ámbito de la cultura clásica encontramos en su obra "breves referencias a la literatura griega y latina, con alguna citación de memoria del "grande poeta Homero", como en el Epistolario cristiano, donde escribe a la letra: "Homero llamó a los reyes de Grecia pastores, sentencia muy celebrada entre los filósofos" 29.

Cita también a Virgilio "gran poeta" ${ }^{30}$; lo mismo que, para la oratoria, a Demóstones ${ }^{31}$, con referencias a Quintiliano y a Cicerón.

En este sentido, Orozco reconoce la autoridad de Aristóteles, que es el autor griego que más veces cita en sus obras, y al que suele llamar "el Filósofo sabio". Lo mismo que a Platón le llama "divino". Igualmente, encontramos en varias ocasiones el nombre del hispano-romano Séneca, calificado por nuestro asceta y místico como "gran filósofo" 32.

28. TEJERINA, Gonzalo, Introducción General a los tratados espirituales del Beato Alonso de Orozco. Vol. I, (Editorial B A C, Madrid 2001), p. XXXV.

29. OrozCO, A. de, Epistolario cristiano para todos los estados. Obras Completas, vol. I. (Imp. del Venerable, Madrid 1736), p. 125.

30. Ibid., o. c., p. 150 (La cita es de la Eneida 172,181-182).

31. Ibid., o. c., p. 193.

32. OROZCO, A. de, Regalis Institutio, (Madrid 1736), p. 52 y 54. 
Con todo ello, Orozco nos demuestra que no tiene ningún complejo al valerse de estos autores paganos, pues considera que llegaron con la razón a la verdad sobre el hombre, el mundo y Dios.

"Cuántas cosas grandes y útiles -escribe- hallaron los filósofos acerca de Dios, fabricador de todo el Orbe; de los Angeles, de la inmortalidad del alma, después de haberles indagado... Aristóteles dijo: El hombre en alguna manera es todas las cosas. Quiso decir que en el hombre estaban sumadas las inteligencias celestiales, pues el alma es espíritu; y estaban como cifradas las cosas corporales, por respecto de ser nuestro cuerpo compuesto de estos cuatro elementos: tierra, agua, fuego y aire... Casi la misma sentencia dijo Platón hablando del ser excelente del hombre, pues entre todos los animales, solamente es dotado de entendimiento y razón, y solamente él conoce a Dios..." 33.

Aparte algunas referencias a las religiones no cristianas, a las que presta menos atención que a la filosofía pagana, Orozco centra su pensamiento y doctrina en "Palabra salvadora".

Tejerina llega a afirmar que la Palabra divina de la revelación sobrenatural es el amplísimo caudal que sustenta y nutre la doctrina de Orozco en todos sus aspectos y lugares ${ }^{34}$.

Nuestro agustino supedita a la sagrada Escritura cualquier experiencia ascética o mística; cualquier visión o revelación... Todo ello se ha de "examinar -escribe- con la sagrada Escritura, la cual pone silencio a todo lo demás, porque es palabra viva de la suma verdad nuestro Dios".

De modo que -concluye tajante- "ni palabra yo en mi vida oiga de Angel, ni de Querubín, sino del santo Evangelio y Escritura sagrada, en la cual no Angel, sino el Señor de los Angeles nos habla cada día" 35.

Para Orozco, que concede también gran autoridad al Antiguo Testamento, éste viene a ser como profecía y figura en la que está oculto el propio Jesucristo. De ahí que considere a sus principales personajes -Isaac, Moisés, David, Salomón-, como figuras anticipadoras de Cristo.

"En verdad, desde hace muchos siglos -escribe- el Antiguo Testamento con sus sombras, figuras y vaticinios de los profetas, nos ha delineado, mejor dicho, nos ha pintado gráficamente el santo Evangelio" 36 .

Sin embargo, en su libro Tratado de las siete palabras que María Santísima habló, declara abiertamente que "el tiempo de la figura ha pasado

33. OrozCo, A. de, Tratado de la suavidad de Dios. Vol. I (Edt. B A C., Madrid 2001), p. 355.

34. TEJERINA, Gonzalo, l. c., p. LIII.

35. OrozCO, A. de, Vergel de Oración. (Edt. B A C., Madrid 2001), p. 59.

36. Orozco, A. de, Certamen de amor santo. Traducción y notas de Fray Pedro Lozano, (Madrid 1914), p. 327. 
y estamos ya en la hora de la plena realidad. Desde la encarnación, todo cambió en la fe de Israel. Con Cristo presente, la figura alcanzó forma definitiva, apareciendo con toda nitidez lo hasta entonces figurado" 37.

"Acabóse la sinagoga -dice en otro de sus libros-; que aquí murió cuanto a todo lo ceremonial y legal. Acabóse la persecución de los enemigos... ${ }^{38}$.

Con todo y con eso "de oro fino es toda la Escritura santa. Preciosa es y un mismo Espíritu Santo la ordenó" 39.

Un dato importante y a destacar en la comprensión de la Escritura es el sometimiento en todo a la santa madre Iglesia. Orozco hace firme profesión de fe en la autoridad de la Iglesia católica, que excede a la de todos los doctores juntos y acredita a la misma Escritura que ella propone a los cristianos, haciendo propia la doctrina de algunos Padres de la Iglesia al respecto, entre ellos, San Agustín y San. Jerónimo. "Custodiemos todas las verdades que la santa y única Iglesia Romana, inspirada por el Espíritu Santo, nos enseña", escribe en su libro El buen combate 40 .

Por lo demás, Orozco tiene muy en cuenta en sus tratados de ascética y mística la tradición teológica, los Padres de la Iglesia, de modo especial -como cabe suponer- san Agustín. De tal modo, que uno de sus biógrafos pudo escribir lo siguiente: "El P. Orozco descubrió en todos sus escritos ser hombre doctísimo en la Theología Escolástica y doctrinas de los Santos Padres: y que si siguiera la Cátedra en lugar del púlpito, leyera con la misma eminencia que predicó. Toca a cada paso en sus libros sutilezas, que sólo con desenvolverlas han ganado fama inmortal los. Theólogos de este tiempo: Agudo en las sentencias, propio en las palabras, suave en el estilo" 41.

Fray Basilio Ponce de León, añadirá que el "el Beato era fundatísimo teólogo y la destreza y brevedad con que habla en materias bien delgadas, lo dicen bien claro. En la Escritura y los SS.PP., tan cursado, que cuando leo así estos libros suyos ${ }^{42}$, como otros, se me refresca la memoria de lo que he leído en los santos" 43 .

37. Orozco, A. de, Tratado de las Siete Palabras que María Santísima habló. Obras Completas, vol. III, (Madrid 1736), p. 197.

38. OROZCO, A. de, Epistolario cristiano para todos los estados. Obras completas, vol. I (Madrid 1736), p. 10.

39. Ibid., o. c., 59 .

40. Orozco, A. de, El buen combate. Traducción y notas de Fr. Pedro Lozano (Madrid 1914), p. 170.

41. MÁrqueZ, Juan, Vida del Venerable, I.c., (Madrid 1648), p. 41ss.

42. Se refiere principalmente al libro de las Confesiones.

43. Orozco, A. de, Epistolario cristiano, 1. c., p. 137. 
Concretamente sobre el doctor de la Gracia, Orozco dirá: "Pero no juzgo que haya otro doctor en quien el opulento y benigno Espíritu haya derramado más ampliamente sus dones que en Agustín, como si hubiera querido representar en una tabla cierto vivo ejemplar de Obispo doctísimo, completo en todos los aspectos.... Entre todos los Doctores de la Iglesia..., brilló a lo largo y a lo ancho por los brillantísimos rayos de su doctrina y de su vida"."

Orozco considera al obispo de Hipona "pilar de la santa Iglesia principal y uno de los cuatro escogidos Doctores" ${ }^{44}$. Hasta el punto de que su doctrina es seguida por los teólogos en cuestiones concretas, o por el mismo Magisterio de la Iglesia.

El P. Tomás Cámara escribe que, "cimentado en los sólidos principios de la filosofía y teología, versado en lenguas sabias, diestro en el manejo de las Escrituras y sobre todas estas partes naturales, animado con la voz de la santísima Virgen, bien pudo tomar la pluma en la mano el Bto. Alonso y trazar a los expatriados hijos de Adán el sendero que lleva a la gloria" 45.

Y lo primero que hace nuestro asceta es prevenir contra la tentación de los que desean "vivir por caminos extraordinarios".

"Ni debéis, hermana, dar lugar a los pensamientos y basfemias del demonio, el cual tienta a las almas para que deseen ver por maravillas y milagros lo que creen por la fe"...

Lo que le recomienda es la petición que hacía san Agustín: "Señor, suplico a vuestra Majestad me reveléis mis pecados, y no quiero ver otra cosa en esta vida, para que puestos los ojos en mí y conociéndome tan pecador, dé voces y diga como aquel publicano: Dios mío, habed misericordia de mí". Estas maravillas pedid, hermana, y desead, porque en este valle de lágrimas no hay más que ver" 46.

Asceta de las virtudes cristianas, Orozco comienza por exponer "lo rara y delicadísima" que es la virtud de la humildad; si bien, dice luego que es "encanto de los cielos".

Citando a santo Tomás, Orozco escribe que la humildad da hambre y apetito de Dios, y por tanto se llaman los humildes hambrientos... Esta humildad es hermana de la magnanimidad y andan a una; de manera que así como la magnanimidad convida al hombre a querer cosas grandes, la humildad le detiene, para que se estime en poco y no presuma cosa alguna de sí 47 .

44. Ibid., lo. c., 106.

45. CÁmARA, Tomás, Vida y Escritos del Beato Alonso de Orozco. Imp. y Lib. de la Vda. de Cuesta e hijos (Valladolid 1882), p. 474.

46. Orozco, A. de, Regla de la vida cristiana, t.II (Madrid 1736), p. 368.

47. OROZCO A. de, Epistolario cristiano. t. I. 
Lógicamente, el P. Orozco no podía ocultarse a los elogios y a las alabanzas que de todas partes -desde el palacio real, a las personas más sencillas y pobres- le llegaban hasta su celda del convento de San Felipe el Real. Entonces, humilde de verdad, exclamaba: "¡Oh Santo Dios, qué tormento es para un humilde oir alabanzas propias! Digo humilde, porque la humildad se afrenta cuando es honrada, y la soberbia se alegra, aunque para su mal y perdición. $\mathrm{Y}$ así entenderemos la turbación de la humildísima Virgen María, cuando el ángel le dio tantos títulos de alabanza, llamándola toda graciosa y bendita entre todas las mujeres. ¡Dichosa el alma que con las injurias se alegra, y con las alabanzas se turba!" 48.

De este modo, podríamos ir recorriendo las distintas virtudes cristianas, pues para todas ellas tiene una doctrina acertada y saludable consejo.

Hablando de la modestia, dice que no debemos tener en poco "el tratamiento honesto de este César (el cuerpo humano), para que el espíritu que es de Dios, se dé a Dios; pues el Espíritu Santo en los Cantares dice a su Esposa, el alma, ser huerto dos veces cerrado".

Cuando se interne por los caminos de la devoción, ofrecerá una doctrina clarísima, distinguiendo la verdadera de la falsa. "No llamamos devoción las lágrimas corporales; no la ternura de corazón; porque todo esto se halla algunas veces en personas que están en pecado mortal.

La devoción verdadera es una presteza que siente el alma, una prontitud maravillosa y ligereza para obrar la ley de Dios y poner en efecto lo que es santo y bueno. Y así dice la divina Escritura que los hebreos ofrecieron joyas y ofrendas para el edificio del Tabernáculo con prontitud y ánimo devoto, esto es, con alegría y sin pesadumbre. De esta autoridad saca santo Tomás qué cosa es devoción. Y porque esta devoción da ligereza al alma para todo lo que es servicio de Dios, según lo que dijo David 'corrí por el camino de vúestros mandamientos, Señor, cuando ensanchasteis mi corazón'; por tanto, diremos que devoción y suavidad del Señor todo es uno, porque una causa naturalmente produce un mismo efecto" 49.

En la época del P. Orozco había autores religiosos que vacilaban mucho sobre la frecuencia del sacramento de la comunión y aun del sacrificio de la santa misa. Nuestro asceta y místico no dudó nunca y se opuso a estos autores, como lo vemos en varios de sus libros.

Así, en Monte de contemplación, le dice Agustín a su discípulo Orosio:

"Acordáos, hermano, que en el primer día de nuestro camino propusimos de

48. OrozCO, A. de, La guarda de de la lengua. T. III, c. X Madrid (1736), p. 430.

49. OrozCo, A. de, Tratado de la suavidad de Dios. Obras completas, Edt. BAC, vol. I, c. XXXVI (Madrid 2001), p. 459. 
cada un día, dándonos nuestro Dios salud y fuerza, recibir el Santísimo Sacramento del altar; pues nuestro oficio del sacerdocio y los grandes frutos que de celebrar misa a los vivos y difuntos fieles resultan lo demanda, según ya largamente en la primera jornada tratamos". 50 .

Y por si el teólogo bracarense tenía algún remilgo, añade: "No es engañéis diciendo no me siento devoto para celebrar, porque eso es decir que arda la lámpara sin echarle aceite, o el fuego sin leña. El santo David dice que los carbones fríos son encendidos en la presencia de este santísimo fuego. Lleguémonos luego a él; que si flacos somos, él es nuestra fortaleza; y si pecadores, él es nuestra salud y remedio; y si tibios, él mismo se llamó fuego abrasador por su inmensa caridad y amor".

Sabemos que nuestro santo padeció de escrúpulos que le hicieron sufrir y padecer mucho en el alma y aun en el cuerpo. Pues bien, experimentado en esta materia, se extendió mucho en diversos tratados, procurando animar a las almas atribuladas con tales angustias y temores.

Quizá en Memorial de amor santo es donde más se extiende en esta materia. Arremete contra el enemigo común del hombre -que es "el Maligno"-, y pide al alma atribulada, que no le haga caso; pero, sobre todo, que acuda a hombres sabios y prudentes que le aconsejerán cómo vencerlo, "porque los letrados y sabios son sanidad de toda la tierra", según dice la Escritura.

Pero le aconseja que no ande buscando demasiado entre los confesores, pues ganaría muy poco en la pacificación de su espíritu: "No quiero decir - enseña- que andes rodeando muchas tierras para buscar este sabio y santo médico, haciéndote ídolo de alguno que sea, pareciéndote no haber otro en la tierra; porque esta presunción es ya muchas veces ocasión de caída. Bastarte debe el consejo del sabio, pues te dice que todos te sean pacíficos, y uno de mil el consejero. Quiero decir, que a todos los Padres espirituales estimes en mucho, dado que uno sea particular médico de tu conciencia; porque si de muchos quisieres tomar consejo, a las veces menos aprovecharás, como haya diversas opiniones y pareceres las más veces entre los sabios" 51 .

Magnífico consejo, valedero hoy y siempre, el de nuestro asceta Alonso de Orozco.

Finalmente, para dar término a este párrafo, he aquí cómo se expresa en su amor y devoción por san Agustín -maestro en estas materias-, en una de sus Declamaciones, por citar solamente un ejemplo: " $\mathrm{OH}$ abundante río de

50. OROZCO, A. de, Monte de contemplación. Edt. BAC, vol. I, (Madrid 2001), p. 187ss.

51. OROZCO, A. de, Memorial de amor santo. t.II (Madrid 1736), p. 485 
sabiduría, más fecundo que el Nilo y más redundante que el Océano! ¡Oh vaso admirable, capacísimo de los secretos de Dios! ¡Oh piélago casi inmenso de los Sacramentos de Dios! ¿Qué diré de ti? Toda alabanza es inferior a ti y las cosas que pueden ser dichas por nosotros no alcanzan la cima de tu altura" 52 .

\section{b. Alonso de Orozco, místico experimental y místico doctrinal}

Nada tiene, pues, de extraño que nuestro asceta y místico sea seguidor constante del Doctor de la Gracia, acudiendo frecuentemente a su doctrina y remitiéndose a él, una y otra vez, en mil cuestiones como fiel y devotísimo discípulo suyo.

El especialista en temas religiosos, Baldomero Jiménez Duque ha dejado escrito que, al hablar del padre Orozco como místico, tiene importancia la influencia que pudiera haberse dado en él del platonismo, "ya que la cultura renacentista, al comenzar la Edad Moderna, trajo consigo un revival de admiración y de estudios del mismo" .

Al fin y al cabo, los agustinos por herencia de su Fundador, con su platonismo intelectual, pero no abstracto, sino también psicológico y vital, jugoso, detectaron dicha influencia platónica; como lo vemos en Fray Luis de León, Malón de Chaide, Cristóbal Fonseca y en nuestro Alonso de Orozco.

El estuvo impregnado de ese espíritu y de las perspectivas del seudo Dionisio. Páginas atrás, hemos visto cómo a Platón le llama "divino filósofo"; como lo encontramos en la obra Tratado de la suavidad de Dios ${ }^{53}$.

Esto no obstante, su doctrina espiritual y en concreto sobre la contemplación mística, es sencillamente cristiana, recreado todo ello por las enseñanzas e invitaciones a cultivar la interiorización que tanto subrayó san Agustín, en parte quizá influenciado éste por Plotino.

Esto supuesto, no hará falta decir que Orozco ha sido un místico en el sentido más riguroso de la palabra. "Que ha vivido el misterio cristiano en profundidad y vivencialmente, que su vida mística ha sido privilegiada y extraordinaria. Que estuvo dotado de carismas y de fenómenos milagrosos

52. Orozco, A. de, Declamationes in laudem Praecellentissimi Praesulis et Doctoris Ecclesiae Aurelii Augustini, $2^{\mathrm{a}}$ parte.

53. JIMÉNEZ DUQUE, Baldomero, Teoría y experiencia mística en el Beato Alonso de Orozco, en "Figura y obra de Alonso de Orozco, O. S. A. (1500-1591)". Edición de Rafael Lozano, "Revista Agustiniana" (Madrid 1992), p. 214. 
abundosamente... Los procesos de beatificación lo proclaman. Y sus biógrafos, como el P. Cámara, que sigue siendo hasta hoy el principal de todos" 54 .

Fray Alonso de Orozco declara que a la alta mística se llega por medio de la oración. Y no es que vayamos a identificar la vida mística con la vida de oración. Pero sí afirmar con nuestro santo que la oración silenciosa, meditativa y contemplativa es lugar privilegiado para el encuentro vivencial con el misterio, con la presencia divina. Y Orozco fue una extraordinaria síntesis por la altura de contemplación y de acción 55 .

Un testimonio vivo y singular de esa fuerte vida mística de Fray Alonso la encontramos en su libro de las Confesiones. Es un escrito mistográfico o biográfico muy interesante -escribe nuevamente don Baldomero Jiménez Duque-, perteneciente a un género literario poco cultivado en aquella época -ni nunca, en verdad-, que, sin estar a la altura de san Agustín ni de Santa Teresa, sí que participa de la sinceridad y de la confianza que delatan e inspiran aquellos grandes genios en sus conocidas obras similares. Por él podemos asomarnos a su alma tan afectiva y tierna, y tan gratificada por Dios. Experiencias místicas, muchas de ellas extraordinarias, que tuvieron repercusión efectiva en su vida personal y apostólica. Las incesantes exclamaciones devotas que llenan el libro, nos revelan el secreto de su corazón. Esas bellísimas elevaciones, que él no puede por menos de engastar también en sus otros libros para comunicar algo de sus sentimientos íntimos a los demás.

Son muchos los ejemplos que podríamos aportar ${ }^{56}$. Como testimonio vivo, valgan los dos siguientes: "Estando yo en aquella quietud, me acordé de aquellas palabras del Santo David: «Gustad y ved cuán suave es el Señor». Qué bien dicho está. Gustad y ved, porque en el gusto de vuestro santo espíritu con nueva luz, y vista es el alma alumbrada, perdiendo de vista todo lo que es momentáneo, y asentando su corazón y deseo en Vos, Criador mío, Bien infinito y eterno...57.

Hablando de la "solicitud" que Cristo tiene de los que le sirven, escribe al final del capítulo $\mathrm{V}$ del Libro tercero: "Aprovécheme a mí la doctrina que enseño y haga fruto en las almas cristianas. No me olvidaré jamás de una vez que, durmiendo, os vi en una Cruz, y me mirábais con unos ojos tan amorosos,

54. Orozco, A. de, Tratado de la suavidad de Dios. Obras completas. Edición de (Salamanca 1895), p. 13.

55. JIMÉNEZ DUQUE, B., 1. c., p. 216.

56. Ibid., 1. c., p. 217.

57. El lector curioso puede tomar en sus manos el citado libro y consultar desde la página 97 (Edición 1736), donde "Síguense algunos particulares favores y mercedes que Ntro. Señor hizo al Venerable P. Fr. Alonso de Orozco (OROZCO, A. de, Libro tercero de las Confesiones. Edición de (Madrid 1736), p. 97ss. 
que parecía que salían de ellos saetas encendidas de amor. ¡Oh, Señor, qué suavidad sintió mi alma en aquel breve tiempo que duró esta vista piadosa y amorosa! Loado seais Vos por todos estos favores, que con este siervo inútil obrasteis" 58.

En honor a la verdad, hay que confesar que Orozco es más asceta que místico. Es un autor predominantemente popular y ascético, que habla de las virtudes y de su práctica, de la oración sencilla, de sus grados y maneras más accesibles a todos, como páginas atrás ha podido quedar demostrado.

Pero igualmente ha sabido elevarse a las alturas de la vida contemplativa. Como escritor místico el P. Cámara señala el libro titulado Monte de contemplación, como ejemplo admirable de altos vuelos. Pero junto a este libro, hay que señalar, y àsí lo hace Monasterio, las obras Memorial de amor santo y Tratado de la suavidad de Dios.

Monte de contemplación viene a ser, en gran parte, un delicioso diálogo entre Agustín y Orosio ${ }^{59}$, donde se exponen cuatro jornadas para subir al monte del Señor, y al fin se tratan cuatro grados de contemplación con una figura que los suma todos: es la salida de Getsemaní, mientras que Vergel de oración sería la senda del Calvario.

Monte, donde camina el alma deseosa de contemplar los altos misterios que en él se obraron. El diálogo -escribe Monasterio a la letra- "es muy digno del ilustre autor de los Nombres de Cristo, a quien, si se le anticipó en la estima del idioma y su apología, no le fue en zaga al manejar la Escritura, base imprescindible, según su dictamen del edificio de la vida espiritual" 60 .

"Ya es tiempo, dice nuestro místico por boca de Orosio, que tratéis de la contemplación, pues ya medianamente tengo entendido lo que de la oración en este primer huerto y vergel santo me habéis platicado. Deseo seguir a mi Redentor hasta el otro vergel, adonde dice san Juan que fue enclavado en la cruz y muerto por la salud del hombre. Vergel es y monte bien encumbrado de altos misterios que en él se obraron ${ }^{61}$.

Menester fuera -le reponde Agustín- haber sido nosotros vecinos y moradores de estos gloriosos vergeles de Getsemaní, adonde oró nuestro

58. Orozco, Libro de las Confesiones, 1. c., p. 101.

59. Ibid: 1. c., lib. III, c. V. p. 93.

60. Paulo Orosio fue un historiador y teólogo visigodo, nacido en Braga el año 390 y muerto en Tarragona el 418. Ordenado que fue de sacerdote, tuvo que huir de la persecución sueva y se trasladó a Hipona el año 414, donde se convirtió en discípulo de san Agustín y escribió una obra contra los priscilianistas, titulada: Commonitorium adversus origenistas; y otras obras contra los pelagianos.

61. MONASTERIO CODINA, Ignacio, Místicos Agustinos Españoles. Editirial Agustiniana (El Escorial 1929), p. 152. 
Redentor, y del monte Calvario, adonde orando murió, para entender tales sacramentos, porque, si san Pablo dice que no se atreve a declarar lo que por experiencia, mediante Cristo, no hubiese sentido ${ }^{62}$ ¿con qué osadía, con qué atrevimiento hablaré yo lo que aún por mis pecados ignoro? Baste, hermano, que no sólo de corrida el alma ha de gozar de estos dos Huertos que dije, más aún, como quien hace casa y mora en ella, ha de señalar suelo, conversando y contemplando muy particularmente cada misterio que con tanta caridad, paciencia y humildad el Rey del cielo para nos salvar obró" 63.

Sobre el libro Historia de la Reina Sabá, el mismo Monasterio dice que lo que nos cuenta la sagrada Escritura ${ }^{64}$, no es otra cosa, en la doctrina de Orozco, que una imagen o símbolo de lo que acontece en la vida espiritual al alma que desea conocer y amar a Dios para poseerle fruitivamente aquí, y por visión intuitiva después.

"Para venir a fin tan deseado -escribe Orozco- nos da gran doctrina la reina Saba, mujer sabia y valerosa, la cual, con deseo de saber más, oyendo la gran fama del rey Salomón, dejó sus reinos de Saba y Egipto y, no sin gran trabajo y costa, vino largo camino hasta entrar en Jerusalén, y, presentada delante de Salomón, manifestó las dudas que tenía al Rey, el cual la respondió tan delicadamente, satisfaciendo a sus cuestiones, que ella quedó admirada y volviendo en sí, alabó al Dios de Israel, que tal rey había proveído en aquel reino" 65 .

Esta bellísima historia, "tan llena de misterios y tan apacible al entendimiento, es la que Orozco trata de exponer en dicho libro, para enseñarnos los principios, los progresos y el coronamiento o término de la vida espiritual.

Esta comienza por el abandono y salida del reino del pecado, y entrando en el de Cristo, verdadero Salomón, por la fe, la esperanza y la caridad, que nos infunde con su divina gracia.

"Cada un alma -escribe nuestro místico- que se convierte a Dios es reina Saba. Es reina, como dice san Jerónimo, porque no reina el pecado en ella, sino Jesucristo. No se ensoñorea la soberbia, no la avaricia, ni la bestia fiera de la lujuria. No tiene mando el tirano Satanás en ella; luego merece título de señora grande y reina; $y$, al contrario, séase quien fuere, si en pecado mortal está, no es señor, sino siervo; no rey, sino esclavo, aherrojado de sus bravas pasiones" 66 .

62. OrozCO, A. de, Monte de contemplación. Edit. BAC (Madrid 2001), p. 169.

63. Rom. $15,18$.

64. OrozCO, A. de, Monte de contemplación, l. c., p. 170

65. III Reyes, c. X.

66. OrozCo, A. de, Historia de la Reina Sabá. Ed. BAC, Obras completas, vol. I (Madrid 2001), prólogo, p. 529. 
El P. Cámara, hablando de este libro, nos dice que se trata de una obra en la cual la belleza literaria se une al conocimiento del corazón humano y la sensibilidad espitual más admirable: "Devocionario más lindo no pudo regalar a la Reina 67 . Pocos libros del venerable escritor, con ser todos tan deleitables, nos causaron tan agradable impresión al leerlos; ni de ellos conservamos tan grato recuerdo como de esta ingeniosa Historia. Así lo entendieron también los lectores piadosos y eruditos, a juzgar por las cuatro o cinco ediciones que de ella se estamparon aun en vida del autor" 68.

Domingo Natal, en la Introducción que hace sobre este hermoso libro en la edición de la Biblioteca de Autores Cristianos (BAC), escribe que el tono y el sentido de la obra es la propia del cristianismo como religión del amor, muy bien asumido por el Beato Orozco y la Escuela Agustiniana. Como ha dicho Ana Bulovas en su estudio sobre el El amor divino en la obra del Beato Alonso de Orozco (Madrid 1975): "La idea que inspira este trabajo es muy fácil de expresar: la vida espiritual del Beato Alonso de Orozco fue fundada sobre el amor divino, y era un ejemplo perfecto de un alma nutrida por la fuente y el sol del amor de Dios ${ }^{69}$. Como diría el P. Bruno Ibeas, la palabra caritas define la espiritualidad agustiniana por ser el emblema fundamental de la experiencia cristiana.

Dice Natal que en este libro se trata de enseñarle al cristiano a escuchar a Cristo, según el ejemplo de la reina Sabá, recogido del Evagelio de San Mateo, para conocerle, servirle y adorarle como nuestro Señor y Salvador.

"Para el Beato Orozco, el hombre es un milagro en el mundo. Es también un mundo en pequeño, como dice Aristóteles, al que cita en bastantes ocasiones. Nuestro Beato admiraba profundamente los grandes inventos de la humanidad, especialmente el reloj, el arte de la navegación y la imprenta. Pero desde el punto de vista religioso, es admirable en el hombre su sed insaciable de Dios que es a la vez su descanso. Insiste el Beato en la conversión, la oración, la confesión, y la comunión, en oir sermón, así como en la caridad y la limosna" 70 .

Sobre el Tratado de la suavidad de Dios, debemos señalar que, entre todos los libros de nuestro Beato constituye una verdadera joya de inapre-

67. Ibid.1. c., c. III, p. 536-37.

68. El libro Historia de la Reina Sabá fue dedicado a la reina doña Isabel de Valois, esposa de Felipe II, la más amada para él de cuantas tuvo, y que murió muy joven.

69. CÁMARA, Tomás, Vida y escritos, p. 179.

70. NATAL, Domingo, La mística agustiniana del amor en el Beato Alonso de Orozco, en "Estudio Agustiniano", 26 (1991) p. 232. 
ciable valor, "regalo para la vista y el oído", "obra de fecundo y sabroso contenido", "para un alma fina y amante del Señor".

Se trata de una obra en la que "su autor se eleva hasta casi tocar las riberas de la patria celestial.

Cámara señala que el P. Orozco se aprovechó de esta obra para dar desahogo a su pecho inflamado y, al mismo tiempo, para ofrecer a los fieles una doctrina que pudiera levantarlos a la contemplación y posesión de bienes tan estimables.

Después de distinguir varias maneras de contemplación en su libro Memorial de amor santo, Orozco advierte en Monte de contemplación, que quien desee "ver el rostro del Luchador poderosísimo y nuestro inmenso Dios", tiene que luchar consigo mismo, "siendo varón de vida activa", ejercitándose en los tres grados (maneras) de contemplación, que acaba de describir ${ }^{71}$.

Pues bien, en el Tratado de la suavidad de Dios, da un paso más adelante y escribe literalmente: "Basta un conocimiento sencillo para la contemplación, la cual más consiste en afectos, que en ciencia, ni delicado entendimiento.

De aquí es que vemos más personas sin letras devotas y que gustan más de Dios, que algunos sabios, porque el cuidado y solicitud que ponen los letrados en saber y entender, ponen los otros en amar a Dios".

"Una fuente que corre por dos caños reparte la fuerza de su corriente en dos partes; mas cerrado el uno, sale con mayor fuerza el agua. Dos potencias principales de nuestra alma son el entendimiento y la voluntad, y es menester que vayamos a la mano al entendimiento, para que el alma ponga toda su fuerza en la voluntad, amando a Dios, en quien el entendimiento halle deleite y más la voluntad" 72 .

Y remata nuestro místico con una cita del "Sabio Filósofo": "En la contemplación de la verdad puso Aristóteles la bienaventuranza del hombre; y aun dijo una cosa grande: que Dios, contemplando a sí mismo su poder, saber, hermosura y bondad, gozaba de la bienaventuranza perpetua" 73 .

Todo el capítulo XVIII de este libro, titulado: "Cómo en la contemplación el alma reposa y halla gran suavidad", es un regalo para quien entre en su lectura con intención devota y recogida. "El fin de la contemplación -señala aquí- es holgarse el alma y descansar en su centro, que es Dios. Y así dijo

71. NatAl, Domingo, Historia de la Reina Sabá. Obras completas. Ed BAC, vol. I, Introducción, p. 522.

72. OrozCO, A. de, Monte de contemplación. Edt. BAC, vol. I (Madrid 2001), c. XXIII, p. 204.

73. OROZCO, A. de, Tratado de la suavidad de Dios. Edt. BAC, vol. I.c. XVIII (Madrid 2001), p. 393. 
san Dionisio que la contemplación pertenece al descanso del alma. Conforme a esto, dijo el sabio: Vuelto a casa, junto a ella descansaré" 74 . Nuestra casa, no edificada con manos, según dice san Pablo, es nuestro Dios, en el cual entramos y descansamos de los trabajos de esta vida, contemplándole aquí por fe y viéndole como en espejo, hasta que en el cielo le contemplemos y veamos en su esencia; de manera que lo que ha trabajado el alma leyendo, meditando y orando, se le da a gustar en la contemplación.

De aquí, es lo que dijo el sabio: 'pues no causa amargura su compañía, ni tristeza la convivencia con ella, sino placer y alegría'" 75 .

Finalmente -para recreo del ojo y del oído-, he aquí otro párrafo del mismo capítulo: "Exclamaba nuestro padre (San Agustín): 'Tarde te amé, belleza tan antigua y tan nueva, tarde te amé' ${ }^{76}$. Así habíamos de llorar todo el tiempo perdido que se empleó en el mundo, no amando y contemplando esta majestad soberana y esta hermosura eterna. Platón, en aquel convite que escribió, me admira en sola lumbre natural las grandezas que dice de la hermosura de Dios. Una cosa, para ser perfectamente hermosa, no la ha de faltar cosa alguna; toda ha de ser acabada, que no parezca por una parte hermosa y por otra fea. También ha de ser por sí hermosa y que no tenga de otra cosa alguna mendigada su hermosura. Finalmente, no ha de ser temporal, que se acabe, sino perpetua y tal -dice este divino filósofo-que es Dios" 77.

Y termina, lleno de amor ardiente por el alma y por Cristo: " $¡ E a$, alma, levanta tus ojos y mira la hermosura de Dios y esposo, y di con la esposa:'Mi amado es fúlgido y rubio, distinguido entre diez mil"... Amale de todo corazón, pues él tanto te amó y tantas mercedes te ha hecho. Reposa en sus brazos, porque digas con verdad lo que en los Cánticos de Salomón se escribe: 'Su izquierda está bajo mi cabeza, y su diestra me abraza' (Cant; 2,6) ${ }^{78}$.

Muy comedido y muy prudente, ya en la Historia de la Reina Sabá había escrito: "Miel es la contemplación, tome cada uno, con tiento y discreción; lo que le basta, no exceda según su estado y fuerzas, no desee robamientos (sic) ni novedades, que suele el demonio entender en estos negocios, como lo hemos visto en nuestros tiempos. Humíllese el cristiano, entienda en rememediar pobres y consolar afligidos, ore y contemple las grandezas de Dios y no quiera sentir más de lo que Dios le quiere dar. Diga con David, cuando va a orar: 'Señor, como un animal soy hecho delante de vos (Sal 73,22). Aquí me

74. ARISTÓTELES, Etica, c. 10.

75. Sab. 8, 16.

76. OrozCo, A. de, Tratado de la suavidad de Dios, 1. c., c.XVIII, p. 392.

77. SAN Agustín, Confesiones, lib. X,27,38.

78. Orozco, A. de, Tratado de la suavidad de Dios, 1. c., c. XVIII, p. 393-394. 
presento delante de mi rey y Señor, nada quiero gustar sino lo que vos queréis que sienta para gloria vuestra y provecho mío'" 79 .

Por otra parte, observamos que Orozco, como místico, en su exposición doctrinal, sigue un ritmo netamente agustiniano. "La contemplación cristiana -enseña Jiménez Duque- es una cointuición de la mente, del entendimiento, del corazón; una vivencia, diríamos ahora, una empatía o encuentro del hombre, de su interioridad cognoscitiva y amorosa toda con el Dios vivo. (En san Agustín, mens, intelectus y cor son a veces casi sinónimos).

Pero subrayará enseguida nuestro Beato, "ahora aquí sobre la tierra sólo puede ser imperfectamente, en el ámbito de la fe. Luego, en el cielo, en la visión, se dará en perfección, en plenitud" 80.

La división o etapas de este ritmo o itinerario ("puertas", las llama Orozco) serían, pues, en primer lugar la lectio divina de la Escritura Santa; luego vendría la meditatio, "rumiando imginativamente o conceptualmente lo leído; a continuación, tendría lugar la oratio, o cultivo del afecto, aspecto afectivo; y finalmente, la contemplatio, o gustación espiritual de todo.

En definitiva, el amor -esto hay que subrayarlo- es el que une al hombre con Dios. "Lo esencial del merecimiento -dirá nuestro santo- no consiste sino en la caridad y no en el fervor de ella, que aquí llamamos devoción" 81.

Sin duda que tiene sabor agustiniano el texto que sigue: "Que pueda volar (el alma) tan alto, que guste de aquella dulzura infinita, nuestro Dios. Y aque aún aquí en este valle de lágrimas... comience ya con la dulzura de la devoción a seguir el vuelo del espíritu y a gustar la suave contemplación" 82 .

Terminemos nuestro estudio con las mismas palabras con que el mencionado Jiménez Duque terminó su conferencia en las Jornadas del Centenario: San Alonso de Orozco "es un gran místico personal y doctrinal. Su figura ha quedado sin embargo siempre en penumbra, a pesar de su presencia y actuación tan destacada en la España del siglo XVI, y a pesar de su abundosa producciín literaria. Pocos escribieron entonces tanto como él. La Inquisición le respetó siempre. Sin duda por la ortodoxia y sencillez de sus escritos, y quizá también por el amparo que las dedicatorias de sus obras a grandes personajes (como la princesa doña Juana) le proporcionaron. Pero él desde la sombra influye en otros autores, como en Diego de Estella, etc. Esa influencia está por estudiar, así como apuradamente sus fuentes de inspiración. Tengo para mí que santa Teresa, gran lectora, leyó sobre todo el Vergel,

79. Ibid., I. c., c. XVIII, p. 394.

80. OrozCo, A. de, Historia de la Reina Sabá, 1. c., c. XX, p. 617.

81. JIMÉNEZ DUQUE, B., o. c., p. 221.

82. Orozco, A. de, Monte de contemplación, l. c., c. VII. Edt. BAC, vol. I, p. 204-208. 
el Monte y el Memorial. Habría que rastrear en sus escritos despacio. Sin duda también san Juan de la Cruz. Pero éste es muy personal y personaliza con personalidad propia, fuera de contadas excepciones, cuanto cae en sus manos" 83 .

Teófilo Aparicio López

Estudio Teológico Agustiniano

Valladolid

83. OrozCO, A. de, Memorial de amor santo, 1. c., c. VII, p. $y 0$

84. JiMENEZ DUQUe, B., o. c., p. 235-236. 